\title{
Distinct epigenetic and gene expression changes in rat hippocampal neurons after Morris water maze training
}

\author{
Sylvia D. Carter, Karen R. Mifsud and Johannes M. H. M. Reul * \\ Neuro-Epigenetics Research Group, School of Clinical Sciences, University of Bristol, Bristol, UK
}

\section{OPEN ACCESS}

Edited by:

Richard G. Hunter,

Rockefeller University, USA

Reviewed by:

Ian C. G. Weaver,

Dalhousie University, Canada

Edo Ronald De Kloet,

Leiden University, Netherlands Jason D. Gray,

Rockefeller University, USA

${ }^{\star}$ Correspondence:

Johannes M. H. M. Reul, Neuro-Epigenetics Research Group, School of Clinical Sciences, University of Bristol, Dorothy Hodgkin Building, Whitson Street, Bristol, BS1 3NY, UK hans.reul@bristol.ac.uk

Received: 27 March 2015 Accepted: 29 May 2015 Published: 16 June 2015

Citation:

Carter SD, Mifsud KR and Reul JMHM (2015) Distinct epigenetic and gene expression changes in rat hippocampal neurons after Morris water maze training.

Front. Behav. Neurosci. 9:156.

doi: 10.3389/fnbeh.2015.00156
Gene transcription and translation in the hippocampus is of critical importance in hippocampus-dependent memory formation, including during Morris water maze (MWM) learning. Previous work using gene deletion models has shown that the immediate-early genes (IEGs) c-Fos, Egr-1, and Arc are crucial for such learning. Recently, we reported that induction of IEGs in sparse dentate gyrus neurons requires ERK MAPK signaling and downstream formation of a distinct epigenetic histone mark (i.e., phospho-acetylated histone H3). Until now, this signaling, epigenetic and gene transcriptional pathway has not been comprehensively studied in the MWM model. Therefore, we conducted a detailed study of the phosphorylation of ERK1/2 and serine10 in histone H3 (H3S10p) and induction of IEGs in the hippocampus of MWM trained rats and matched controls. MWM training evoked consecutive waves of ERK1/2 phosphorylation and H3S10 phosphorylation, as well as c-Fos, Egr-1, and Arc induction in sparse hippocampal neurons. The observed effects were most pronounced in the dentate gyrus. A positive correlation was found between the average latency to find the platform and the number of H3S10p-positive dentate gyrus neurons. Furthermore, chromatin immuno-precipitation (ChIP) revealed a significantly increased association of phospho-acetylated histone H3 (H3K9ac-S10p) with the gene promoters of c-Fos and Egr-1, but not Arc, after MWM exposure compared with controls. Surprisingly, however, we found very little difference between IEG responses (regarding both protein and $\mathrm{mRNA}$ ) in MWM-trained rats compared with matched swim controls. We conclude that exposure to the water maze evokes ERK MAPK activation, distinct epigenetic changes and IEG induction predominantly in sparse dentate gyrus neurons. It appears, however, that a specific role for IEGs in the learning aspect of MWM training may become apparent in downstream AP-1- and Egr-1-regulated (second wave) genes and Arc-dependent effector mechanisms.

Keywords: hippocampus, Morris water maze, histone H3 phosphorylation, immediate early genes, memory, chromatin immuno-precipitation, cognition, stress 


\section{Introduction}

Hippocampus-dependent long-term memory formation is important for allowing adaptation and optimization of behavioral responses when similar circumstances are encountered again. The Morris water maze (MWM) paradigm is frequently used as a model to study spatial memory formation, which involves de novo gene transcription and protein synthesis in the hippocampus. Glucocorticoids secreted in response to a stressful event, such as being placed into the MWM, facilitate hippocampal learning and memory processes (Oitzl and De Kloet, 1992; Sandi et al., 1997; Oitzl et al., 2001; Shors, 2001). Research into the molecular changes underlying hippocampus-dependent memory formation has identified an important role of the ERK MAPK (extracellular signalregulated kinase, mitogen-activated protein kinase) cascade and subsequent induction of the immediate-early genes (IEGs) FBJ murine osteosarcoma (c-Fos), early growth response 1 (Egr-1) and activity-regulated cytoskeletonassociated protein (Arc) (Atkins et al., 1998; Blum et al., 1999; Guzowski et al., 2001; Adams and Sweatt, 2002). Studies using Arc, c-Fos, and Egr-1 knock-out mice, as well as antisense oligodeoxynucleotides, have indicated a necessity for these IEGs in the consolidation of hippocampus-dependent memory (Paylor et al., 1994; Guzowski et al., 2000; Jones et al., 2001; Guzowski, 2002; Plath et al., 2006; Czerniawski et al., 2011).

IEG induction is thought to be regulated by ERK MAPK signaling, however, the exact underlying molecular mechanisms are presently unknown. Activation of the ERK MAPK cascade results in recruitment of nuclear kinases and transcription factors such as Elk-1 and CREB (Xia et al., 1996; Deak et al., 1998; Davis et al., 2000) as well as chromatin modifying enzymes [mitogen- and stress-activated kinase (MSK) and histone acetyl transferases (HATs)], leading to epigenetic changes within the chromatin in sparse dentate gyrus granule neurons (Chwang et al., 2007; Chandramohan et al., 2008; Reul et al., 2009, 2015; Gutierrez-Mecinas et al., 2011; Reul, 2014). The resultant phosphorylation of serine-10 and acetylation of lysine residues within histone $\mathrm{H} 3$ is thought to de-condense (open) the chromatin structure, potentially allowing transcription factors to bind to their responsive elements, leading to transcription of formerly silenced genes (Nowak and Corces, 2000; Cheung et al., 2000a,b; Reul et al., 2009; Mifsud et al., 2011; Trollope et al., 2012).

The functional significance of these molecular changes in dentate gyrus neurons during stress-related memory formation has been studied using the forced swim paradigm. In this test, rats and mice show a passive, adaptive response of increased behavioral immobility when re-exposed to forced swimming. Pre-treatment of rats with either an N-methyl D-aspartate receptor (NMDAR) antagonist, a glucocorticoid receptor (GR) antagonist or an ERK MAPK kinase (MEK) inhibitor, or using MSK1/2 double knockout mice, each blocked histone H3 phospho-acetylation and IEG induction in dentate granule neurons and the consolidation of the behavioral immobility response in a $24 \mathrm{~h}$ (or even 4 -week) forced swim re-test (De Kloet et al., 1988; Chandramohan et al., 2008; Gutierrez-Mecinas et al., 2011).

These ERK MAPK-driven epigenetic modifications may also play a role in IEG induction during memory formation of more pro-active behavioral responses, such as those during spatial MWM learning. However, at present the phosphorylation of ERK1/2, formation of the combinatorial, phosphorylated and acetylated, histone $\mathrm{H} 3$ marks, and induction of the IEGs cFos, Egr-1, and Arc in neurons of the different sub-regions of the dorsal hippocampus has not been investigated within the context of MWM learning. Moreover, the existence of a direct association of this double histone mark with IEG promoters following MWM training has not been studied either. This study, therefore, provides a detailed hippocampal sub-region specific time course of ERK1/2, and H3S10 phosphorylation and c-Fos, Egr-1, and Arc induction in response to MWM training. Changes in these factors in MWM trained rats have been compared with time-matched swim controls as well as naïve baseline animals. Finally, using chromatin immuno-precipitation (ChIP) we determined the association of the combinatorial histone $\mathrm{H} 3$ phospho-acetylation mark with the gene promoters of the IEGs c-Fos, Egr-1 and Arc in response to training in the MWM.

\section{Materials and Methods}

\section{Animals}

Male Lister Hooded rats (140-175 g on arrival) were purchased from Harlan (Oxon, UK) and group-housed (2-4 per cage). Rats were housed under standard lighting (lights on 05:0019:00 h, approximately $100 \mathrm{Lux}$ ) and environmentally controlled conditions (temperature $21 \pm 1^{\circ} \mathrm{C}$; relative humidity $40-60 \%$ ) with food and water available ad libitum. All procedures were approved by the University of Bristol Ethical Committee and by the Home Office of the UK. All rats were handled for at least 5 days prior to experimentation in order to reduce non-specific handling stress on the day of the experiment.

\section{Behavioral Procedures}

The MWM set-up consisted of a circular, stainless steel tank ( $1.8 \mathrm{~m}$ diameter) filled with water $\left(25^{\circ} \mathrm{C} \pm 1\right)$ to a depth of approximately $30 \mathrm{~cm}$. The maze was divided into four virtual quadrants and a transparent platform was placed in the center of the north-east quadrant, submerged $2 \mathrm{~cm}$ below the surface of the water. Visual cues were placed on the walls surrounding the maze. Rats were trained to find the platform, which was kept in a fixed position throughout training. Rats received one training session per day, each comprising four training trials. On the first day only, training trials were preceded by an acclimatization trial, whereby rats were allowed to explore the maze for $3 \mathrm{~min}$ with no platform present. Each training trial was a maximum of $3 \mathrm{~min}$ long, with an inter-trial time of at least $10 \mathrm{~min}$, during which rats were returned to their home cage. For each of the four training trials the rat was placed into the maze, facing the edge, from a different direction (north, east, south, and west). A trial was deemed to be completed if the rat had found the platform, climbed on to it and remained there for $20 \mathrm{~s}$. If the rat had not found the platform within the $3 \mathrm{~min}$, it was 
guided to the platform by hand. Fully trained rats received one training session per day for 4 days, followed by a probe trial on the fifth day. For the probe trial, rats were placed into the maze for $3 \mathrm{~min}$ in the absence of the platform, during which the number of platform zone crossings and the latency to the first platform zone crossing were recorded. After each training session, rats were returned to their home cages, with the same housing conditions as prior to training. For mRNA, protein and ChIP analyses, groups of rats received training on only 1 day and were killed at varying points during and following training. Behavior throughout training was recorded using the Noldus EthoVision video tracking system, version 3 (Noldus Information Technology, Wageningen, Netherlands).

Two control groups were used in our study: (1) Baseline (BL), i.e., naïve rats, killed directly from their home cages; (2) Swim control (SC) rats that swam in the same maze as MWM trained rats and were matched to the MWM condition for both the number and the length of trials, but with no platform present in the maze during their trials. Swim control rats were therefore free to swim and explore the maze for equal amounts of time but there was no active platform location learning for this group.

\section{Immunohistochemistry}

For immunohistochemistry, rats were deeply anesthetized with isoflurane, given a lethal injection of pentobarbital and transcardially perfused with $100 \mathrm{ml}$ ice-cold $0.9 \%$ saline followed by $500 \mathrm{ml}$ of $4 \%(\mathrm{w} / \mathrm{v})$ paraformaldehyde containing $1 \mathrm{mM}$ sodium orthovanadate $\left(\mathrm{Na}_{3} \mathrm{VO}_{4}\right)$ and $50 \mathrm{mM}$ sodium fluoride $(\mathrm{NaF})$ and $0.195 \%$ picric acid in $0.1 \mathrm{M}$ phosphate buffer (PB). Perfused brains were then extracted from the skull and stored at $4^{\circ} \mathrm{C}$ in $0.1 \mathrm{M}$ phosphate buffer $(\mathrm{PB})$ containing $1 \mathrm{mM} \mathrm{Na}_{3} \mathrm{VO}_{4}$ and $50 \mathrm{mM} \mathrm{NaF}$. Unless otherwise stated, all reagents for this study were purchased from Sigma-Aldrich (Dorset, UK).

Separate groups of rats were killed under baseline conditions, immediately after each training trial, as well as at 2, 4, and $8 \mathrm{~h}$ after the start of MWM training. Perfused rat brains were cut into $50 \mu \mathrm{m}$ thick coronal sections using a vibratome (Leica VT 1000S) and the avidin-biotin complex (ABC) method was used to visualize pERK1/2, H3S10p, c-Fos, Egr-1, and Arc in free-floating sections spanning the dorsal hippocampal region [between coordinates (anterior-Posterior) -2.92 and $-3.96 \mathrm{~mm}$ from Bregma, according to the atlas of Paxinos and Watson, 2007]. For H3S10p and pERK1/2 staining an initial antigen retrieval step was carried out and all solutions up to and including the primary antibody solution contained $50 \mathrm{mM} \mathrm{NaF}$ and $1 \mathrm{mM} \mathrm{Na} \mathrm{VO}_{4}$ to inhibit endogenous phosphatases. For $\mathrm{H} 3 \mathrm{~S} 10 \mathrm{p}$ staining, sections were initially incubated with $1 \mathrm{~N} \mathrm{HCl}$ at $45^{\circ} \mathrm{C}$ for $30 \mathrm{~min}$. For pERK1/2, sections were initially incubated with citrate buffer at room temperature (RT) for $90 \mathrm{~min}$. In both cases, sections were then washed with $0.1 \mathrm{M}$ PB with phosphatase inhibitors. All other steps were carried out at RT.

For all antibodies, sections were incubated for $1 \mathrm{~h}$ in blocking solution (50 mM glycine, 2\% Bovine Serum Albumin (BSA), $0.05 \%$ sodium azide and $0.1 \%$ Triton X-100 in $0.1 \mathrm{M} \mathrm{PB}$ ) followed by an overnight incubation with primary antibody; either rabbit polyclonal anti-pERK1/2 [1:200, New England Biolabs (NEB)], rabbit monoclonal anti-phospho histone H3 (S10; 1:400, NEB), rabbit polyclonal anti-c-Fos (1:10,000, Calbiochem, Merck), rabbit monoclonal anti-Egr-1 (1:1000, NEB) or rabbit antiArc (1:1000, kindly donated by Dr. P. Worley, John Hopkins University, Baltimore) in incubation solution (0.8\% BSA, $0.1 \%$ Triton X-100 and $0.05 \%$ sodium azide in $0.1 \mathrm{M} \mathrm{PB}$ ). The antiH3S10p has been used by us before and generates a highly similar staining pattern of sparse dentate gyrus neurons as the anti-H3S10p-K14ac antibody (Chandramohan et al., 2007, 2008) and the anti-H3K9ac-S10p antibody (Mifsud and Reul, unpublished observations). Unfortunately, the H3S10p-K14ac antibody, still commercially available, has lost its specificity for this combinatorial mark in recent years and is not used by us anymore. Sections were then washed in $0.1 \mathrm{M} \mathrm{PB}$ and incubated in biotinylated goat anti-rabbit IgG secondary antibody (1:400 in $0.1 \mathrm{M}$ PB; Vector laboratories) for 1-2 h. This was followed by further washes with $0.1 \mathrm{M} \mathrm{PB}$ and then incubation with avidinbiotinylated peroxidase complex (ABC, 1:400 in 0.1 M PB, Vector Laboratories) for $1 \mathrm{~h}$. The sections were washed again with $0.1 \mathrm{M}$ $\mathrm{PB}$ and the reaction was developed using a $0.03 \%$ solution of $3,3 /$ diaminobenzidine tetrahydrochloride (DAB) with $0.003 \%$ nickel and $0.04 \%$ ammonium chloride in $0.1 \mathrm{M} \mathrm{PB}$ and catalyzed with $0.003 \%$ hydrogen peroxide. Following development, sections were mounted onto poly-L-lysine coated slides and dehydrated with ethanol. Slides were then cover slipped using Histomount (National Diagnostics).

\section{RNA Analysis}

For RNA analysis, the rats were quickly anaesthetised with isoflurane (Merial Animal Health Ltd.) and decapitated; brains were then removed, cut into $1 \mathrm{~mm}$ coronal slices using a brain matrix after which these slices were arranged on a stainless steel box filled with ice. The dentate gyrus (DG) and cornu ammonis (CA) regions of the dorsal hippocampal area were separately dissected from surrounding tissue, using Dumont \#7 forceps (Fine Science Tools, Vancouver, Canada), under a dissection microscope (Leica M295, Leica biosystems), as previously published (Kersante et al., 2013). The region microdissected spanned coordinates (anterior-Posterior) -2.92 and $-3.96 \mathrm{~mm}$ from Bregma, according to the atlas of Paxinos and Watson (2007). Microdissected DG and CA tissue was snapfrozen in tubes in dry ice and stored at $-80^{\circ} \mathrm{C}$.

Rats were killed at baseline, or $30 \mathrm{~min}, 1,3$, or $7 \mathrm{~h}$ after the start of MWM training or SC experiences. Dorsal DG and $\mathrm{CA}$ region tissue samples were homogenized and RNA was extracted using TRI reagent ( $1 \mathrm{ml}$ for CA regions, $500 \mu \mathrm{l}$ for DG) as per manufacturer's instructions. The resulting RNA pellets were dissolved in $30 \mu \mathrm{l}$ of nuclease free water (Ambion). RNA integrity was confirmed by running samples on a $1 \%$ agarose gel with $0.005 \%$ ethidium bromide. Selected samples were also analyzed for integrity with an Agilent 2100 Bioanalyser (Agilent Technologies); all RNA samples analyzed in this way had RNA integrity numbers of between 8.40 and 9.60. RNA concentrations were determined using a NanoPhotometer Pearl (Implen). Total RNA was converted to cDNA using a QuantiTect reverse transcription kit (Qiagen, Manchester, UK) as per the manufacturer's instructions, which included a step to remove DNA contamination. 
Quantitative PCR (qPCR) was used to quantify the mRNA levels of target genes, using primers and dual-labeled probes modified with FAM as the fluorescent dye and TAMRA as the quencher. A combination of ActB, Yhwaz, and Hprt1 were used as reference genes. Primers and probes were designed using primer express software (version 3.0, Life Technologies). See Table 1 for cDNA primer and probe sequences. In a 96-well plate, $2 \mu \mathrm{l}$ of cDNA was added to $18 \mu \mathrm{l}$ of reaction solution [ $1 \mathrm{x}$ TaqMan fast advanced mastermix (Life Technologies), forward and reverse primers $(900 \mathrm{nM})$, probe $(250 \mathrm{nM})$ in nuclease free water (Ambion)] per well. The PCR reaction was carried out in a StepOnePlus real-time PCR machine (Life Technologies). Samples were initially heated to $95^{\circ} \mathrm{C}$ for $20 \mathrm{~s}$ followed by 40 cycles of heating to $95^{\circ} \mathrm{C}$ for $1 \mathrm{~s}$ and cooling to $60^{\circ} \mathrm{C}$ for $20 \mathrm{~s}$. The efficiency of each primer and probe set was used to calculate the relative mRNA expression ratio using the Pfaffl method (Pfaffl, 2001), normalizing the PCR readouts for the target genes to those of the reference genes.

\section{Chromatin Immuno-Precipitation (ChIP)}

Rats were killed under baseline conditions or at $30 \mathrm{~min}$ after the start of MWM or SC procedures. Due to the limited size of the rat hippocampus and the requirement of sufficient amounts of chromatin, each sample for ChIP was prepared from hippocampus tissue of two rats. Therefore, for the preparation of each chromatin sample, the hippocampus tissue of two rats was cross-linked in $1 \%$ formaldehyde solution containing $5 \mathrm{mM}$ sodium butyrate (NaBut), phosphatase inhibitors [1 PhosSTOP Phosphatase Inhibitor Cocktail Tablet/10 ml (Roche)] and 0.1 mM PMSF in $1 \mathrm{x}$ Phosphate-buffered saline (PBS) at RT for $10 \mathrm{~min}$ after which glycine was added to a final concentration of $200 \mathrm{mM}$. The mixture was rotated at RT for $5 \mathrm{~min}$ and then centrifuged $\left(5 \mathrm{~min}, 6000 \mathrm{~g}, 4^{\circ} \mathrm{C}\right)$. The pellet was washed three times (with a centrifuge step between each wash) in ice-cold PBS with $5 \mathrm{mM} \mathrm{NaBut,} 1 \mathrm{mM} \mathrm{Na} \mathrm{VO}_{4}$, $5 \mathrm{ng} / \mathrm{ml}$ aprotinin, $2 \mathrm{mM}$ AEBSF and phosphatase inhibitors (1 PhosSTOP Phosphatase Inhibitor Cocktail Tablet/10 ml). The pellet was then re-suspended in ice-cold lysis buffer $(50 \mathrm{mM}$ Tris- $\mathrm{HCl} \mathrm{pH}$ 8.0, $150 \mathrm{mM} \mathrm{NaCl}, 5 \mathrm{mM}$ EDTA $\mathrm{pH} 8.0,0.5 \% \mathrm{v} / \mathrm{v}$ Igepal, $0.5 \%$ Sodium deoxycholate, $1 \%$ SDS, $5 \mathrm{mM} \mathrm{NaBut,} 2 \mathrm{mM}$ AEBSF, $1 \mathrm{mM} \mathrm{Na}_{3} \mathrm{VO}_{4}$, 1x dilution of protease inhibitor solution from Complete Ultra EDTA-free protease inhibitor tablets [Roche) and phosphatase inhibitors (1 PhosSTOP Phosphatase Inhibitor Cocktail Tablet $/ 10 \mathrm{ml}$ )] and rotated at $4{ }^{\circ} \mathrm{C}$ for $15 \mathrm{~min}$.

The lysate was sheared by sonication on high power for three sets of 10 cycles ( $30 \mathrm{~s}$ on and $60 \mathrm{~s}$ off) using a cooled Bioruptor (UCD-300; Diagenode). Samples were then centrifuged (10 min, $21,000 \mathrm{~g}, 4^{\circ} \mathrm{C}$ ) and the supernatant (containing the sheared chromatin) was collected. An aliquot of chromatin was taken from each sample to be prepared and used as input DNA. Other aliquots of chromatin from each sample were 10-fold diluted in dilution buffer $(50 \mathrm{mM}$ Tris- $\mathrm{HCl} \mathrm{pH} \mathrm{7.4,} 150 \mathrm{mM}$ $\mathrm{NaCl}, 5 \mathrm{mM}$ EDTA pH 7.4, $1 \%$ triton X-100, 0.1\% w/v sodium deoxycholate, $5 \mathrm{mM}$ NaBut, $1 \mathrm{mM}$ AEBSF, 1x dilution of protease inhibitor solution from Complete Ultra EDTA-free protease inhibitor tablets (Roche), phosphatase inhibitors (1 PhosSTOP Phosphatase Inhibitor Cocktail Tablet/10 ml) and then rotated with rabbit polyclonal histone $\mathrm{H} 3$ (acetyl K9, phospho S10) antibody (Abcam) overnight at $4{ }^{\circ} \mathrm{C}$. This antibody specifically recognizes the combinatorial mark $\mathrm{H} 3 \mathrm{~K} 9 \mathrm{ac}-\mathrm{S} 10 \mathrm{p}$ and presents a higher binding to c-Fos and Egr-1 gene promoters in ChIP assays than the anti-H3S10p antibody (Reul, unpublished observations). These observations in the hippocampus indicate that if $\mathrm{H} 3 \mathrm{~S} 10$ is phosphorylated, then the neighboring $\mathrm{K} 9$ (and K14 Chandramohan et al., 2007) is acetylated, which corresponds with past in vitro studies (Barratt et al., 1994). The anti-H3K9acS10p antibody, rather than the anti-H3S10p-K14ac antibody, was used for ChIP because recent lots of the latter antibody have lost their stringent specificity for binding the dual H3S10p-K14ac mark (Reul lab, unpublished observations). For each sample, a $100 \mu \mathrm{l}$ aliquot of PureProteome Protein A magnetic beads (Merck Millipore) was washed twice with $0.5 \%$ BSA in $1 \mathrm{x}$ PBS and rotated with $0.5 \% \mathrm{BSA} / \mathrm{PBS}$ overnight at $4^{\circ} \mathrm{C}$.

The following day, the antibody-chromatin mixtures were added to the beads and rotated at $4^{\circ} \mathrm{C}$ for $3 \mathrm{~h}$. Next, the beads were washed three times with ice-cold RIPA buffer (10 mM Tris$\mathrm{HCl} \mathrm{pH} 7.4,1 \mathrm{mM}$ EDTA, 0.1\% SDS, 0.5 mM EGTA, 1\% triton $\mathrm{X}-100,0.1 \%$ sodium deoxycholate, $140 \mathrm{mM} \mathrm{NaCl}, 1 \mathrm{x}$ dilution of protease inhibitor solution from Complete Ultra EDTA-free protease inhibitor tablets (Roche), phosphatase inhibitors (1 PhosSTOP Phosphatase Inhibitor Cocktail Tablets $/ 25 \mathrm{ml}$ ), $1 \mathrm{mM}$ AEBSF, $5 \mathrm{mM} \mathrm{NaBut)}$ and twice with ice-cold $1 \mathrm{x}$ Tris-EDTA buffer. The bound fraction was then eluted from the beads in two 15-min elution steps with regular vortexing, using elution buffer 1 (10 mM Tris- $\mathrm{HCl} \mathrm{pH} 7.4,50 \mathrm{mM} \mathrm{NaCl}$, and 1.5\% SDS) and elution buffer $2(10 \mathrm{mM}$ Tris- $\mathrm{HCl} \mathrm{pH} 7.4,50 \mathrm{mM} \mathrm{NaCl}$, and $0.5 \%$ SDS). The protein-DNA crosslinks were reversed by adding $\mathrm{NaCl}$ to a final concentration of $200 \mathrm{mM}$ to the bound samples and the input samples, and incubating at $65^{\circ} \mathrm{C}$ overnight.

Next, the bound and input samples were incubated sequentially with ribonuclease A from bovine pancreas, (final concentration of $125 \mu \mathrm{g} / \mathrm{ml}$ ) for $1 \mathrm{~h}$ at $37^{\circ} \mathrm{C}$ and proteinase $\mathrm{K}$ from Tritirachium album (final concentration of $125 \mu \mathrm{g} / \mathrm{ml}$ ) for $3 \mathrm{~h}$ at $37^{\circ} \mathrm{C}$. A QIAquick PCR purification kit (Qiagen) was used to purify the immuno-precipitated DNA, as per the manufacturer's instructions. Following this, the concentration of double stranded DNA was measured with a high-sensitivity double-stranded DNA assay kit using a Qubit 2.0 Fluorometer (Life Technologies). Bound DNA product and inputs were diluted to $0.05 \mathrm{ng} / \mu \mathrm{l}$ and $0.5 \mathrm{ng} / \mu \mathrm{l}$ respectively in nuclease free water $\left(\mathrm{nfH}_{2} \mathrm{O}\right)$.

Quantitative PCR (qPCR) was used to quantify the levels of target genes within the bound and input fractions using primers and dual-labeled probes modified with FAM as the fluorescent dye and TAMRA as the quencher. Primer and probe sets [designed using primer express software (version 3.0)] used after ChIP are shown in Table 2. Primers and probes were designed to target CREB responsive elements (CREs) in the proximal promoters of the IEGs. $\mathrm{qPCR}$ was principally performed as described above; samples ( $0.1 \mathrm{ng}$ Bound fraction; $1 \mathrm{ng}$ Input fraction) were run in triplicate and a standard curve was performed using serial dilutions of rat brain genomic DNA ( $100 \mathrm{ng} / \mu \mathrm{l}$; BioChain, CA, USA) as standards. The amount of target DNA for each sample was calculated by comparing 
TABLE 1 | Primers and probe sequences used in RNA analysis, including gene symbol and accession number for the target genes.

\begin{tabular}{|c|c|c|c|c|}
\hline Gene symbol & Accession number & Forward primer sequence & Reverse primer sequence & Probe sequence \\
\hline$A c t B$ & NM_031144.3 & GACCCAGATCATGTTTGAGACCTT & AGAGGCATACAGGGACAACACA & AACACCCCAGCCATGTACGTAGCCATC \\
\hline Ywhaz & NM_013011.3 & TGCTGCTGGTGATGACAAGAA & CATCTCCTIITTGCTGATITCAAA & TGGACCAGTCACAGCAAGCATACCAAGAA \\
\hline Hprt1 & NM_012583.2 & CCTCCTCAGACCGCTITCC & CATAACCTGGTTCATCATCACTAATCA & CATGTCGACCCTCAGTCCCAGCG \\
\hline c-Fos & NM_022197.2 & CAGCCAAGTGCCGGAATC & GCAACGCAGACTTCTCGTCTा & ATACGCTCCAAGCGGAGACAGATCAACTT \\
\hline Arc & NM_019361.1 & GGGTGGCTCTGAAGAATATTGG & CACCGAGCCCTGTTTGAACT & AGATCCAGAACCACATGAATGGGCCA \\
\hline Egr1 & NM_012551.2 & AAGACACCCCCCCATGAAC & CTCATCCGAGCGAGAAAAGC & CCCGTATGCTTGCCCTGTTGAGTCC \\
\hline
\end{tabular}

TABLE 2 | Primers and probe sequences used in ChIP analysis, including gene symbol and Ensemble gene ID for the target genes.

\begin{tabular}{|c|c|c|c|c|}
\hline & Ensemble gene ID & Forward primer sequence & Reverse primer sequence & Probe sequence \\
\hline c-Fos & ENSRNOG00000008015 & ТTССССССТССАGTTТСТСТ & TCAGCTGGCCGCTITATAGAAG & TTCCGCTCATGACGTAG \\
\hline Egr1 & ENSRNOG00000019422 & GCTCTTGGATGGGAGGTCTTC & TCCGCCGTGACGTACATG & TCCTCCCGGTCGGTCCT \\
\hline $\operatorname{Arc}$ & ENSRNOG00000043465 & TGAGGGCAAATAGCATGTAATAACC & CAGCCCGGAGTGACTAATGTG & CTTAGCTTCACCCTCGCTGCTCAGGAC \\
\hline
\end{tabular}

the CT values from the bound and input fractions with the standard curve. After correcting for differential loading (1 ng input compared with $0.1 \mathrm{ng}$ bound), enrichment was calculated using the following equation: Bound fraction/ Input fraction $(\mathrm{B} / \mathrm{I})$.

\section{Statistical Analysis}

The statistical and graphical package used to analyze data was GraphPad Prism 5 (GraphPad Software, San Diego, CA, USA). The MWM behavioral data were expressed as the average number of seconds taken to find the platform per trial or per day. Differences between trials or days were analyzed using repeated measures One-Way analysis of variance (ANOVA) followed by Dunnett's post-hoc test. Performances of SC and MWM groups in the probe trial were compared using unpaired Student's $t$-tests.

Immunohistochemical data were expressed as the average number of immuno-positive neurons counted in a dentate gyrus, or a selected region of CA1 or CA3, in a $50 \mu \mathrm{m}$ section of the dorsal hippocampus. Three sections were counted, per rat, by an experimenter blind to the treatment of the animal being counted. In the case of Egr-1 staining in the CA1, the majority of neurons appeared immuno-positive for Egr-1, although staining intensity varied between experimental groups. ImageJ software (Schneider et al., 2012) was, therefore, used to analyze the Egr-1 staining in this brain region. The CA1 region was outlined and an average gray value was determined. This gray value was normalized (in order to adjust for any differential levels of development) based on the gray value determined in an un-stained region, representing background staining, adjacent to the pyramidal cell layer.

Relative RNA expression is presented as a fold-change over baseline levels after normalization to reference genes, whilst ChIP data is expressed as fold change in enrichment over baseline levels. Group means \pm SEM are shown in the figures and samples sizes are stated in each case in the figure legends. Immunohistochemistry, RNA and ChIP data were statistically analyzed using One-Way ANOVA followed by Dunnett's or Bonferroni post-hoc tests where appropriate.
Linear regression analysis was used to analyze correlations between numbers of immuno-stained neurons and behavior during MWM training. In all cases, $P<0.05$ was accepted as statistically significant.

\section{Results}

\section{Acquisition and Retention of the MWM Task}

Over the course of 4 days of MWM training, rats learnt the location of the hidden platform, showing decreasing average latencies to the platform across days. The average latency to find the hidden platform was significantly lower on the second, third and fourth day of training than on the first and by the final training day rats were able to find the platform in an average time of $22.9 \pm 3.4 \mathrm{~s}(n=12)$, compared with an average of $74.6 \pm 5.8 \mathrm{~s}$ on the first day, indicating that the performance of the rats improved with training (Figure 1A). During the 3-min probe trial in the absence of the platform, MWM-trained rats crossed the platform zone an average of $7.8 \pm 0.9$ times compared with only $2.1 \pm 0.2$ times in the SC group (Figure 1B). In addition, the average latency to the first crossing of the platform zone was $16.9 \pm 5.4 \mathrm{~s}$ in the MWM-trained group, compared with $91.3 \pm 15.3 \mathrm{~s}$ in the SC group (Figure 1C). As the largest improvement was seen between the first and second training days, all subsequent investigations into the molecular changes occurring in hippocampal neurons during training focused on the first day of training.

\section{MWM Training Leads to an Increase in the Phosphorylation of ERK1/2 and H3S10, and Induction of Immediate Early Genes in the Dentate Gyrus and CA Regions}

The phosphorylation of ERK1/2 and H3S10, and the induction of c-Fos, Egr-1, and Arc was analyzed in the DG, CA1, and CA3 during 1 day of MWM training and up to $8 \mathrm{~h}$ later. Immunohistochemical analysis in the dorsal hippocampus showed nuclear and cytoplasmic pERK1/2 staining in granule 


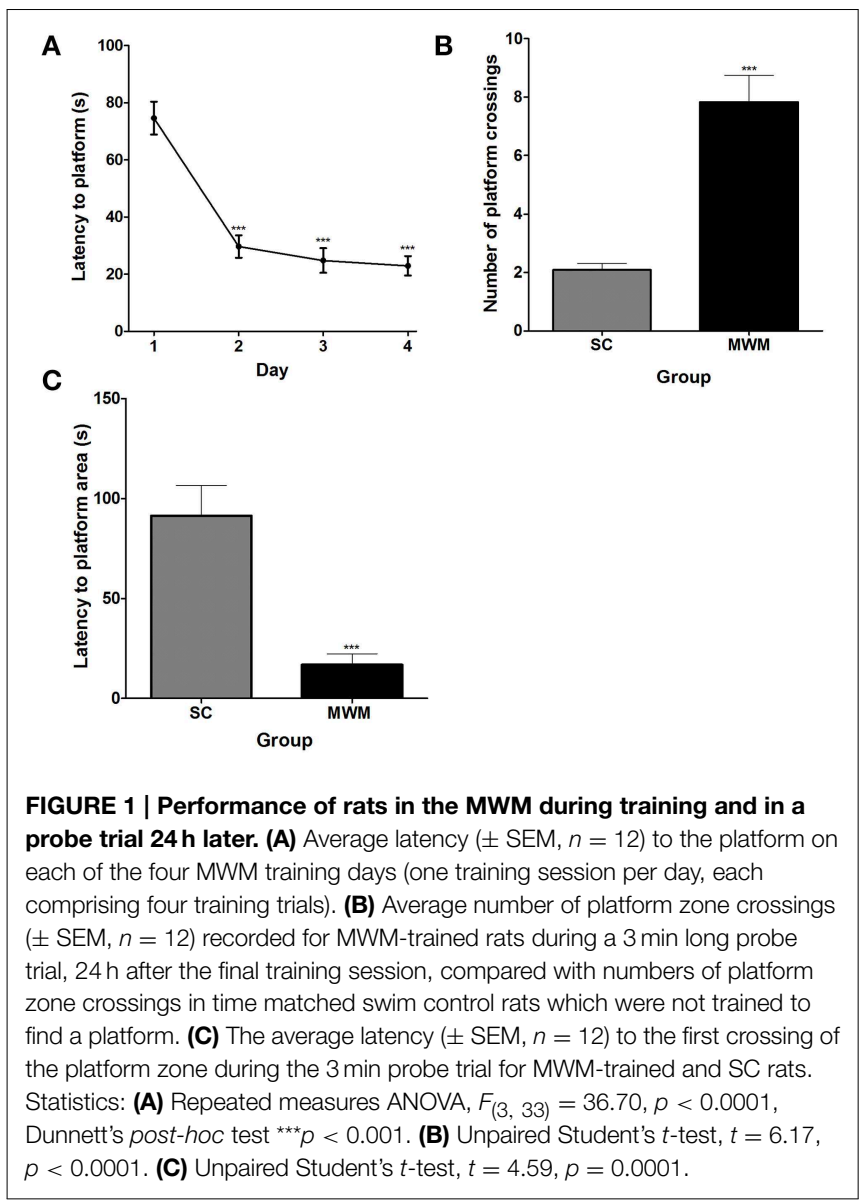

neurons within the granular cell layer of the DG, with a clear increase in the proportion of immuno-stained neurons after MWM exposure, predominantly observed in the dorsal blade (Figures 2A,B). Immuno-staining for H3S10p, c-Fos and Egr-1 each revealed a sparse, nuclear-specific staining of DG granule neurons at baseline, with increased numbers of immuno-stained neurons and increased staining intensity after MWM training, also predominantly in the dorsal blade (Figures 2C-H). Immuno-staining showed Arc to be both nuclear and cytoplasmic, with increases observed in numbers of immuno-positive neurons in the DG after MWM (Figures 2I,J).

Phosphorylation of ERK1/2 in the dentate gyrus was rapid, with a maximal increase in pERK1/2 positive neurons immediately after the initial 3-min acclimatization trial in the MWM. Levels declined steadily throughout training and by the end of the third training trial were no longer significantly different from baseline levels (Figure 3A). Numbers of H3S10ppositive neurons in the DG were also significantly higher than baseline by the end of the initial acclimatization trial, but numbers peaked after the second training trial (approximately $30 \mathrm{~min}$ into training) and were still significantly higher than baseline at the end of the final training trial (approximately $1 \mathrm{~h}$ after the start of training) (Figure 3B). A significant increase in c-Fos positive neurons in the dentate gyrus was seen between $30 \mathrm{~min}$ and $2 \mathrm{~h}$ after the start of training, peaking

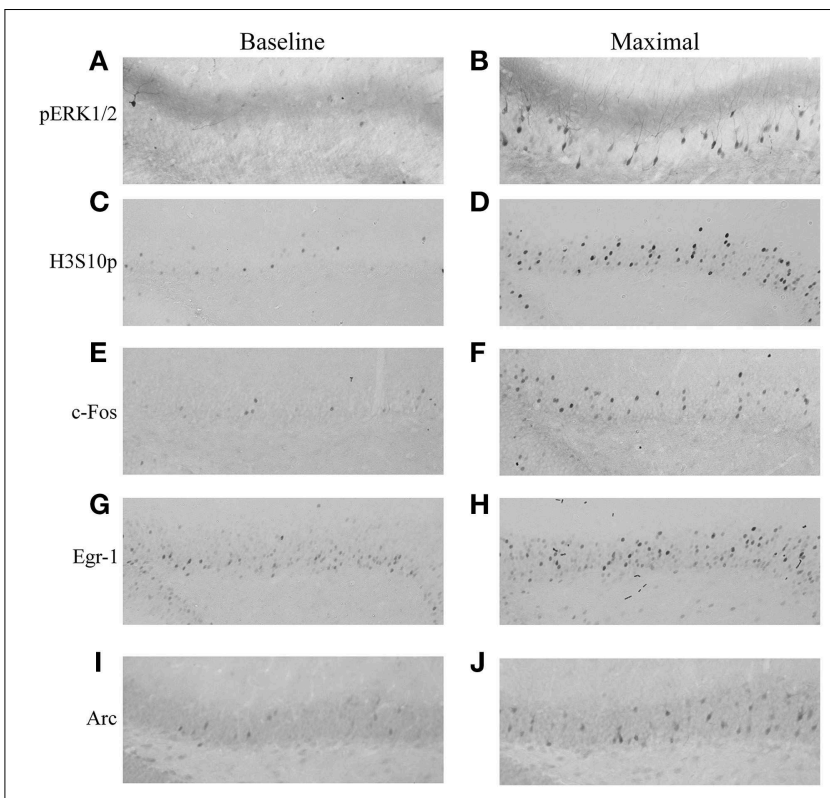

FIGURE 2 | Immunohistochemical staining of pERK1/2, H3S10p, c-Fos, Egr-1, and Arc in the DG under baseline conditions and after MWM training. Rats were killed either under baseline conditions or at different stages of MWM training. Representative images of the dorsal blade of the DG are shown for (A) pERK1/2 under baseline conditions, (B) pERK1/2 at maximal induction (immediately following the acclimatization trial), (C) H3S1Op under baseline conditions, (D) H3S1Op at maximal induction (immediately following the second training trial), (E) c-Fos under baseline conditions, (F) c-Fos at maximal induction (immediately following final training trial), (G) Egr-1 under baseline conditions, (H) Egr-1 at maximal induction $(2 \mathrm{~h}$ after the start of training), (I) Arc under baseline conditions, (J) Arc at maximal induction $(2 \mathrm{~h}$ after the start of training). Magnification: 200 -fold.

at $1 \mathrm{~h}$, whilst numbers of Egr-1 positive neurons increased significantly above baseline between 1 and $2 \mathrm{~h}$ after the start of MWM training (Figures 3C,D). In contrast, numbers of Arcpositive neurons were significantly higher than baseline at alltime points studied, even up to $8 \mathrm{~h}$ after the start of training, with peak Arc expression found $2 \mathrm{~h}$ after the start of training (Figure 3E).

Immunohistochemical staining for pERK1/2, H3S10p, c-Fos, Egr-1 and Arc was also analyzed in the CA3 and CA1 regions of the hippocampus. Numbers of immuno-positive neurons were counted from one microscope view (x 20 magnification) within the CA1 and CA3, as shown in Figure 4A. Changes in numbers of pERK1/2 immuno-positive neurons in the CA3 and CA1 were similar to the DG, with numbers peaking immediately after the acclimatization trial and gradually declining throughout training (Figures 4B,C). Staining for phosphorylated H3S10 in the CA regions was less intense than in the DG and occurred later, peaking after the first training trial and remaining significantly higher than baseline for $1 \mathrm{~h}$ in the CA3 region and $30 \mathrm{~min}$ in the CA1 region (Figures $4 \mathrm{D}, \mathbf{E}$ ). The numbers of c-Fos-positive neurons increased above baseline levels after the third training trial and peaked at $1 \mathrm{~h}$ in the CA1 and at $2 \mathrm{~h}$ in the CA3 (Figures 4F,G). In contrast to the DG, Egr-1 showed a very rapid increase in the $\mathrm{CA} 3$ and numbers of immuno-positive 


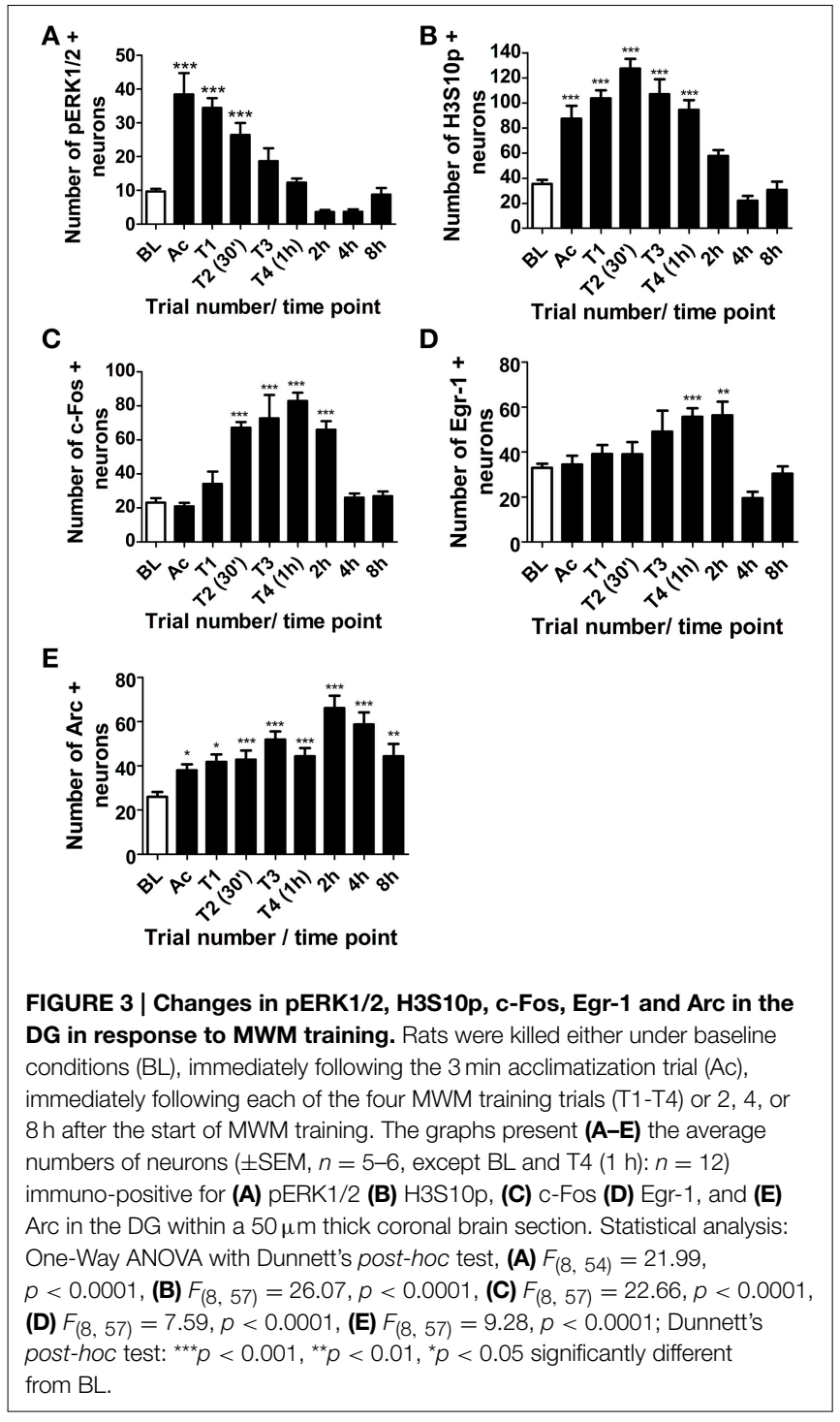

neurons were significantly higher than baseline for the duration of training (Figure 4H). Egr-1 staining in the CA1 region was visible in most cells at baseline, with an increase in staining intensity between 1 and $2 \mathrm{~h}$ after the start of MWM training (Figure 4I). Arc immunostaining in the CA regions was not analyzed as staining was not discernible and did not appear to differ from baseline at any time point investigated.

As we have previously shown that glucocorticoid hormones via GRs facilitate ERK MAPK signaling to the chromatin (Gutierrez-Mecinas et al., 2011), changes in plasma corticosterone levels in the MWM paradigm were investigated. Training in the MWM led to a significant increase in plasma corticosterone levels, which peaked at the end of training (approximately $1 \mathrm{~h}$; Figure S1A). By $4 \mathrm{~h}$, plasma corticosterone levels were no longer significantly higher than baseline, and by $8 \mathrm{~h}$ plasma corticosterone levels had risen again over baseline levels, due to normal circadian rhythm (Figure S1A).

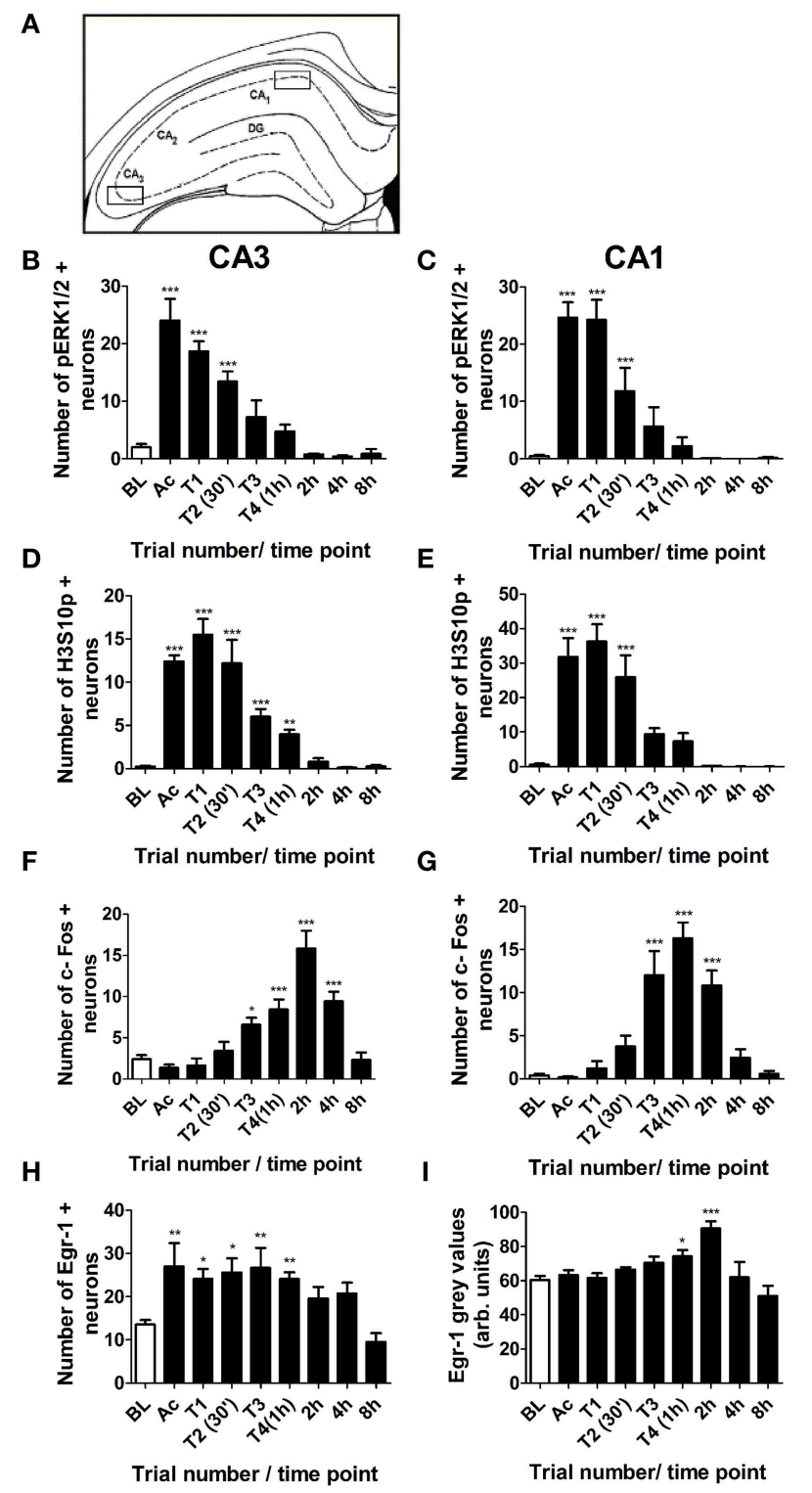

FIGURE 4 | Changes in pERK1/2, H3S10p, c-Fos and Egr-1 in the CA3 and CA1 in response to MWM training. Rats were killed either under baseline conditions (BL), immediately following the $3 \mathrm{~min}$ acclimatization trial (Ac), immediately following each of the four MWM training trials (T1-T4) or 2, 4, or $8 \mathrm{~h}$ after the start of MWM training. The graphs present the average numbers of neurons ( \pm SEM, $n=5-6$, except $\mathrm{BL}$ and T4 (1 h): $n=12)$ in the regions of the CA3 and CA1 shown in (A) which were immuno-positive for (B) pERK1/2 in the CA3, (C) pERK1/2 in the CA1, (D) H3S10p in the CA3, (E) H3S10p in the CA1 (F) c-Fos in the CA3, (G) c-Fos in the CA1, (H) Egr-1 in the CA3, and (I) Egr-1 in the CA1 within a $50 \mu \mathrm{m}$ thick coronal brain section. Arc staining in the CA regions was indistinct and was therefore not analyzed. Statistical analysis: One-Way ANOVA with Dunnett's post-hoc test, (B) $F(8,54)=25.02, p<0.0001$, (C) $F_{(8,54)}=20.08$, $p<0.0001$, (D) $F_{(8,57)}=34.83, p<0.0001$, (E) $F_{(8,57)}=22.06$, $p<0.0001$, (F) $F_{(8,56)}=16.63, p<0.0001$, (G) $F_{(8,56)}=20.87$, $p<0.0001$ (H) $F_{(8,57)}=5.10, p<0.0001$ (I) $F_{(8,57)}=6.10$ $p<0.0001$. Dunnett's post-hoc test: ${ }^{* *} p<0.001$, ${ }^{* *} p<0.01,{ }^{*} p<0.05$ significantly different from baseline. 


\section{The Number of H3S10p-Positive Neurons in the DG after Training Positively Correlates with the Average Latency to Find the Platform During Training}

Over the course of 1 day of MWM training, the time taken for the rats to find the hidden platform decreased significantly (Figure 5A), however, there was some variation in performance between individual rats. A significant, positive correlation was found between average latency to find the platform over the course of 1 day of training and the numbers of neurons immunopositive for $\mathrm{H} 3 \mathrm{~S} 10 \mathrm{p}$ at the end of training ( $1 \mathrm{~h}$ time point) in the DG (Figure 5B). There was no such correlation between performance in the MWM and numbers of c-Fos, Egr-1, or Arc immuno-positive neurons (Figures 5C-E). There was also no correlation between MWM performance and numbers of neurons immuno-positive for any of these factors in either the CA3 or the CA1 regions of the hippocampus (data not shown).

\section{Hippocampal H3S10p and IEG Changes in MWM-Trained Rats are Highly Similar to the Changes Occurring in SC Rats}

IEG mRNA levels were measured $30 \mathrm{~min}, 1,3$, and $7 \mathrm{~h}$ after the start of MWM training and compared with mRNA levels

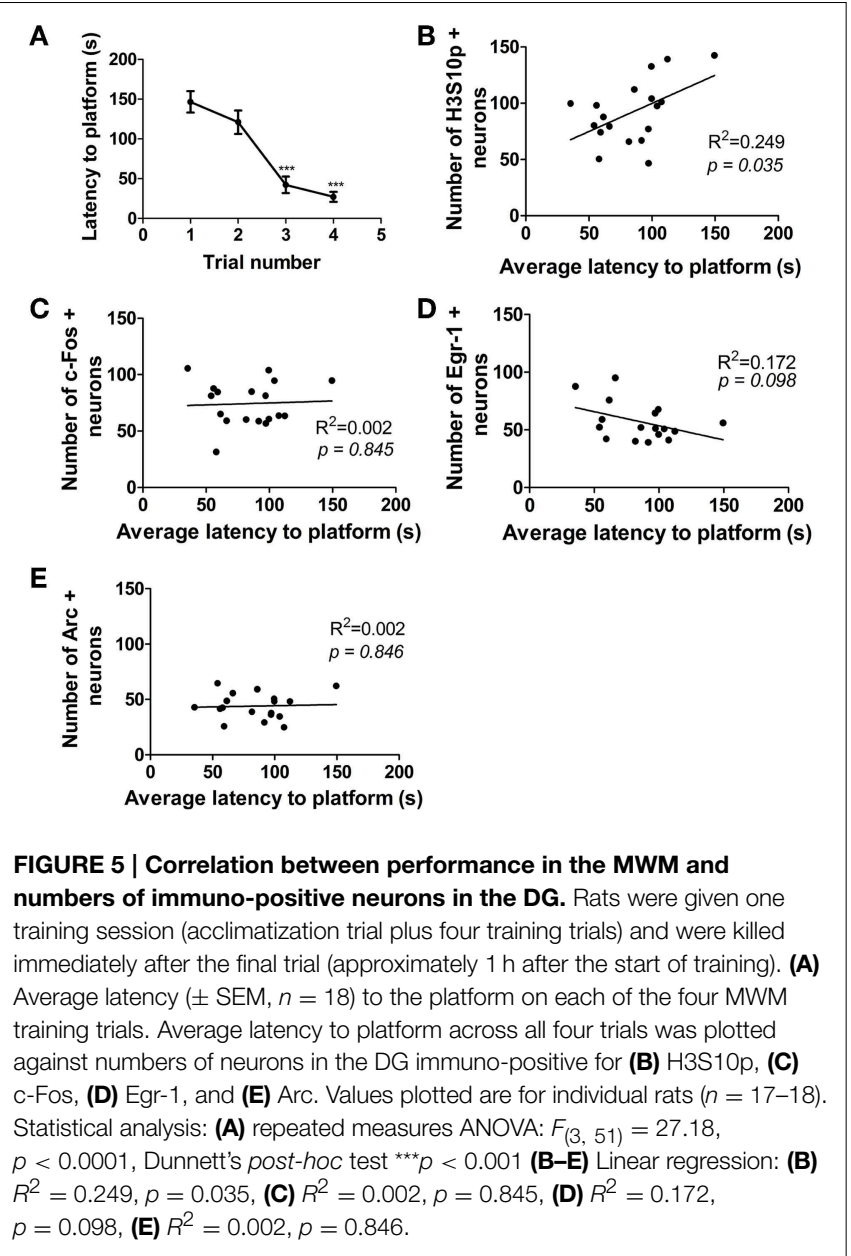

in matched SC rats. In both the DG and CA regions, $c$-Fos mRNA levels were increased in MWM trained and SC groups (Figures 6A,B). At $1 \mathrm{~h}$ after the start of training DG $c$-Fos levels in the SC group were significantly higher than in the MWM group (fold changes over baseline; $3.9 \pm 0.2$ and $3.1 \pm 0.2$ respectively). Egr-1 mRNA levels were significantly increased over baseline levels in the DG and CA regions in both SC and MWM groups at $30 \mathrm{~min}$ and $1 \mathrm{~h}$, before returning to baseline at $3 \mathrm{~h}$ (Figures 6C,D). Arc mRNA was also up-regulated in the DG and $\mathrm{CA}$ regions in both $\mathrm{SC}$ and MWM groups (Figures 6E,F) In the DG, the up-regulation was extended, with $\operatorname{Arc}$ mRNA levels still significantly higher than baseline $3 \mathrm{~h}$ after training. There were no significant differences in Egr-1 or Arc mRNA levels between SC and MWM groups at any time point studied in either the DG or CA regions.

Immunohistochemical analyses were carried out on dorsal hippocampal slices taken from MWM-trained and SC rats at $30 \mathrm{~min}$ and $1 \mathrm{~h}$ post training, in order to compare levels of

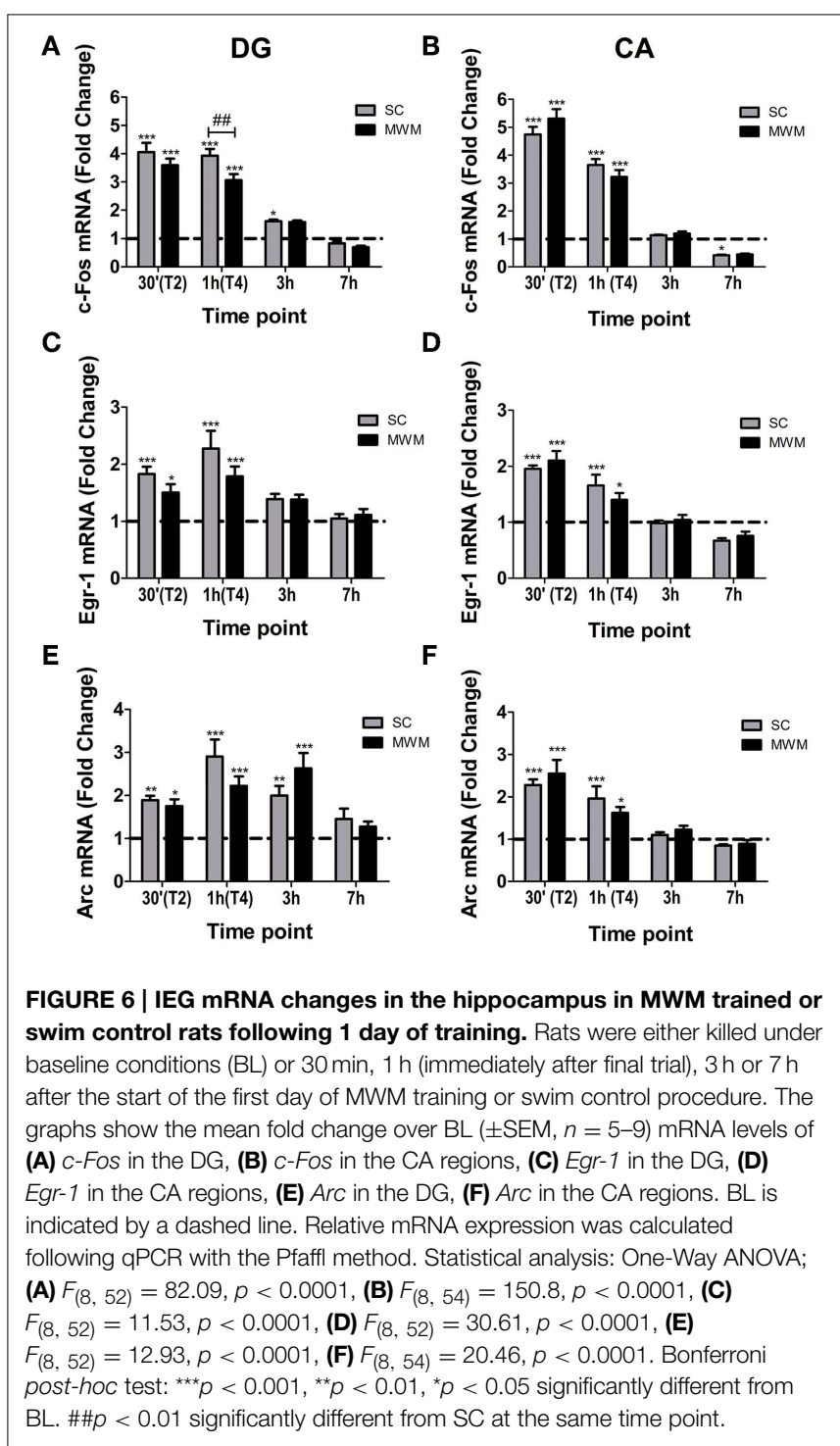


H3S10p and IEG proteins in hippocampal neurons between the two experimental conditions. There were, however, no significant differences between SC and MWM groups in the numbers of immuno-positive neurons at either time point (Table 3).

Plasma corticosterone levels were increased significantly above baseline in both MWM and SC groups, but there were no significant differences between MWM and SC groups at either time point studied (Figure S1B).

\section{There is Increased Association of H3K9ac-S10p with c-Fos and Egr-1 Gene Promoters after SC and MWM}

ChIP for the dual histone mark H3K9ac-S10p was carried out using chromatin of whole hippocampus tissues collected $30 \mathrm{~min}$ after the start of MWM or SC. We found a significant increase in the association of $\mathrm{H} 3 \mathrm{~K} 9 \mathrm{ac}-\mathrm{S} 10 \mathrm{p}$ at the promoters of the IEGs c-Fos and Egr-1, whilst levels of the dual histone mark at the Arc promoter remained unchanged across all conditions (Figure 7).

\section{Discussion}

The present study shows that exposure to the MWM leads to a rapid, transient phosphorylation of pERK1/2, a more protracted phosphorylation of $\mathrm{H} 3 \mathrm{~S} 10$, and transcription and translation of the IEGs c-Fos, Egr-1, and Arc predominantly in sparse neurons of the DG. The time course of induction of each of these components is in line with the concept of rapid ERK/MAPK activation leading to phospho-acetylation of histone $\mathrm{H} 3$, which in turn alters chromatin conformation allowing induction of c-Fos and Egr-1 (Figure 8); a sequence of events also shown to occur in the DG in response to forced swimming (Chandramohan et al., 2008; Gutierrez-Mecinas et al., 2011). We have previously shown that these molecules are co-localized within the same DG granule neurons after forced swimming or novelty exposure (Chandramohan et al., 2007; Gutierrez-Mecinas et al., 2011). Therefore, it is likely that this cascade of events also occurs within specific DG neurons following MWM training.

In addition to the changes seen in the DG, phosphorylation of ERK1/2 and H3S10 was also observed in sparse neurons of the $\mathrm{CA} 3$ and CA1 regions (although staining for H3S10p in the CA regions was much fainter than in the DG). The IEGs c-Fos and Egr-1 were also induced in the CA regions, however, there was no visible change in Arc. Importantly, using ChIP, we showed an increase in the association of phospho-acetylated histone $\mathrm{H} 3$ with the promoter regions of c-Fos and Egr-1 after MWM training, implying a direct role of this epigenetic modification in activity-dependent transcription of these genes.

The H3S10p epigenetic mark has been found to form solely in the DG in response to FS and novelty stress (Chandramohan et al., 2007, 2008; Gutierrez-Mecinas et al., 2011); however, the current study has shown that this mark is also increased in CA3 and CA1 pyramidal neurons after MWM training, albeit

TABLE 3 | Immuno-positive neurons in hippocampal sub-regions after MWM or SC experiences.

\begin{tabular}{|c|c|c|c|c|c|c|c|}
\hline \multicolumn{8}{|c|}{ Number of immuno-positive neurons } \\
\hline & & BL & $\operatorname{SC~} 30^{\prime}$ & MWM 30' & SC $1 \mathrm{~h}$ & MWM $1 \mathrm{~h}$ & Statistics \\
\hline \multirow[t]{4}{*}{ DG } & H3S10p & $35.2 \pm 3.7$ & $86.8 \pm 3.8^{*}$ & $98.1 \pm 6.3^{*}$ & $79.7 \pm 6.3^{\star}$ & $87.4 \pm 12.6^{\star}$ & $\begin{array}{l}F_{(4,25)}=11.24 \\
P<0.0001\end{array}$ \\
\hline & c-Fos & $15.4 \pm 1.8$ & $37.0 \pm 3.0^{*}$ & $40.0 \pm 3.7^{\star}$ & $51.7 \pm 4.2^{\star}$ & $57.2 \pm 5.2^{\star}$ & $\begin{array}{l}F_{(4,25)}=19.98 \\
P<0.0001\end{array}$ \\
\hline & Egr-1 & $39.9 \pm 7.5$ & $23.8 \pm 6.5$ & $32.2 \pm 9.7$ & $42.5 \pm 7.1$ & $60.2 \pm 10.8$ & $\begin{array}{l}F_{(4,24)}=2.49 \\
P=0.0705\end{array}$ \\
\hline & Arc & $17.5 \pm 2.2$ & $45.7 \pm 4.5^{\star}$ & $32.9 \pm 3.3^{*}$ & $46.9 \pm 2.8^{\star}$ & $43.1 \pm 4.3^{\star}$ & $\begin{array}{l}F_{(4,25)}=12.11 \\
P<0.0001\end{array}$ \\
\hline \multirow[t]{3}{*}{ CA3 } & H3S10p & $0.4 \pm 0.2$ & $9.1 \pm 2.2^{*}$ & $10.9 \pm 2.3^{*}$ & $4.9 \pm 0.6$ & $4.6 \pm 1.2$ & $\begin{array}{l}F_{(4,24)}=7.68 \\
P=0.0004\end{array}$ \\
\hline & c-Fos & $2.6 \pm 0.7$ & $3.0 \pm 0.7$ & $4.2 \pm 1.3$ & $7.1 \pm 1.5$ & $9.3 \pm 2.5^{\star}$ & $\begin{array}{l}F_{(4,25)}=3.80 \\
P=0.0151\end{array}$ \\
\hline & Egr-1 & $15.9 \pm 2.4$ & $28.8 \pm 2.9$ & $29.5 \pm 3.5$ & $29.9 \pm 4.0$ & $33.5 \pm 4.8^{\star}$ & $\begin{array}{l}F_{(4,23)}=3.15 \\
P=0.7234\end{array}$ \\
\hline \multirow[t]{3}{*}{ CA1 } & H3S10p & $0.3 \pm 0.2$ & $17.1 \pm 5.9^{\star}$ & $19.5 \pm 3.4^{*}$ & $7.4 \pm 2.2$ & $5.1 \pm 1.6$ & $\begin{array}{l}F_{(4,24)}=7.29 \\
P=0.0005\end{array}$ \\
\hline & c-Fos & $0.3 \pm 0.2$ & $4.0 \pm 1.3$ & $3.9 \pm 2.3$ & $8.9 \pm 1.7^{\star}$ & $10.2 \pm 1.9^{*}$ & $\begin{array}{l}F_{(4,25)}=6.03 \\
P=0.0015\end{array}$ \\
\hline & Egr-1 & $60.9 \pm 2.9$ & $66.86 \pm 1.1$ & $62.7 \pm 2.0$ & $67.2 \pm 2.7$ & $74.9 \pm 2.3^{\star}$ & $\begin{array}{l}F_{(4,25)}=5.48 \\
P=0.0028\end{array}$ \\
\hline
\end{tabular}

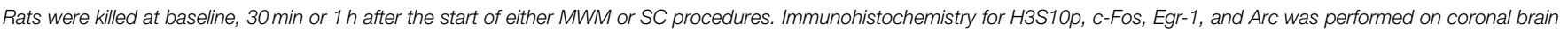

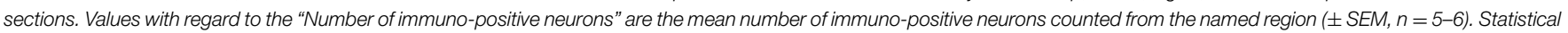

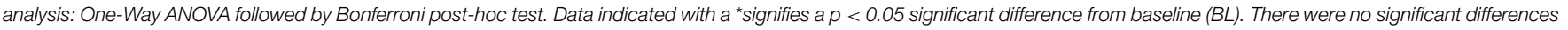
between SC and MWM at any time point. "Statistics" indicates the ANOVA result. 


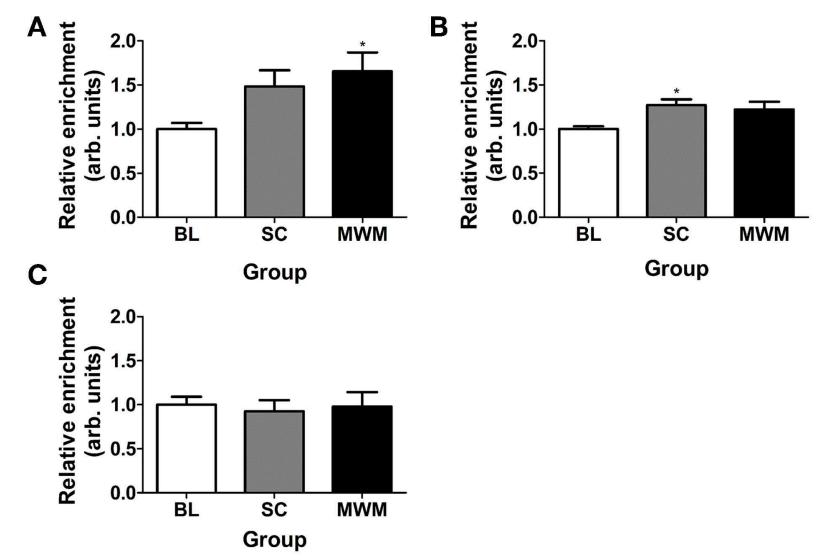

FIGURE 7 | Changes in enrichment of H3K9ac-S10p at the promoters of $\boldsymbol{c - F o s , ~ E g r - 1 , ~ a n d ~ A r c ~ a f t e r ~ S C ~ a n d ~ M W M . ~ R a t s ~ w e r e ~ k i l l e d ~ e i t h e r ~ u n d e r ~}$ baseline conditions or 30 min after the start of the first day of MWM training or swim control procedure. Chromatin immuno-precipitation was carried out on whole hippocampus tissue. The graphs show the relative enrichment of H3K9ac-S10p at (A) the c-Fos promoter, (B) the Egr-1 promoter, (C) the Arc promoter. The enrichment for each group was calculated by dividing the quantity of target DNA in the H3K9ac-S10p-bound fraction by the quantity of DNA in the input fraction (bound over input, $\mathrm{B} / \mathrm{I}$ ) and data is expressed as a ratio over baseline enrichment $[ \pm$ SEM, $n=3-6$ (every replicate comprised hippocampal chromatin from two rats)]. Statistical analysis: One-Way ANOVA; (A) $F_{(2,15)}=3.98, p=0.0369$, (B) $F_{(2,14)}=4.06, p=0.0407$, (C) $F_{(2,15)}=0.08, p=0.9204$. Dunnett's post-hoc test: * $p<0.05$ significantly different from baseline $(\mathrm{BL})$.

to a lower staining intensity in each neuron. Our observations correspond with earlier findings of David Sweatt and colleagues who, using western blot analysis, observed H3S10p formation in the mouse CA1 region after contextual fear conditioning (Chwang et al., 2006). It may be speculated that MWM training, due to its repetitive nature, is a stronger stimulus for phosphoacetylation of H3S10 than FS. This notion is supported by a study by Sassone-Corsi and colleagues, who showed an increase in H3S10 phosphorylation in the CA1 and CA3, in addition to the DG, after kainate injection (Crosio et al., 2003); in further agreement with our study, they found staining for H3S10p in the CA regions to be much less intense than in the DG. Notably, our study shows how rapidly $\mathrm{H} 3 \mathrm{~S} 10$ can be phosphorylated, with a significant increase in H3S10p positive neurons seen even after the initial 3-min acclimatization trial.

The spatio-temporal pattern of c-Fos activation followed a very similar pattern in the DG, CA1 and CA3, however, this was not the case for Egr-1 and Arc. Expression of Egr-1 was distinct in each hippocampal sub-region. In the DG, Egr-1 showed a characteristic sparse nuclear staining, with an increase in the number of stained neurons seen $1-2 \mathrm{~h}$ after the start of training, whereas in the CA1 region, constitutive levels of Egr-1 were high, with staining visible in most cells, the intensity of which increased $1-2 \mathrm{~h}$ after the start of training. In the CA3 region, baseline levels of Egr-1 appeared similar to those in the DG, however, a very rapid ( $<5 \mathrm{~min}$ ) increase in Egr-1 positive neurons was seen, which lasted for the duration of training. It is possible that this finding may reflect roles of Egr-1 in the different functions

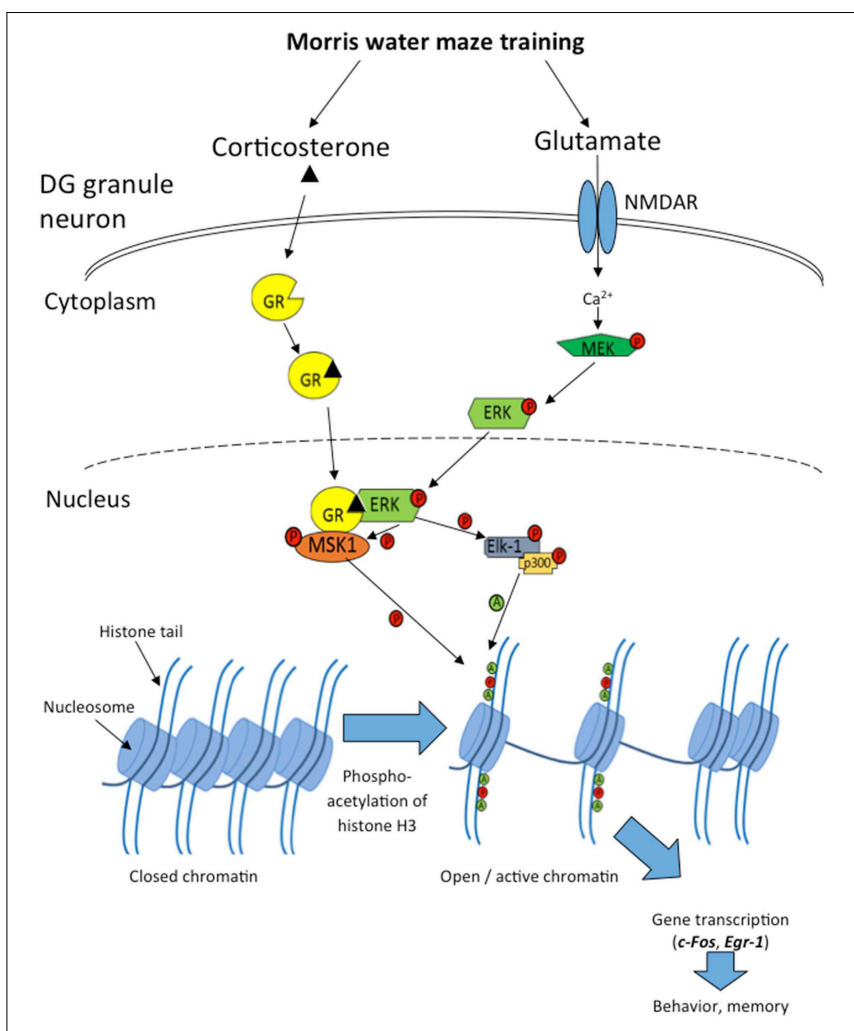

FIGURE 8 | Diagram showing the cascade of events in sparse DG neurons following MWM training, leading to c-Fos and Egr-1 transcription. Introducing a rat to the MWM activates NMDARs, causing initiation of the MAPK/ERK cascade within the neuron, leading to phosphorylated ERK1/2 entering the nucleus. Concurrently, glucocorticoid hormone-occupied GR also translocates to the nucleus where it physically interacts with $\mathrm{pERK} 1 / 2$, allowing the phosphorylation of the nuclear kinases MSK1 and Elk-1. MSK1 then phosphorylates histone $\mathrm{H} 3$ at serine 10, and Elk-1recruits and phosphorylates p300, a histone acetyl transferase, which acetylates histone $\mathrm{H} 3$ at lysine 9 , lysine 14 and possibly other lysine residues. These modifications result in the opening of the chromatin structure and facilitation of transcription of genes such as c-Fos and Egr-1, which are involved in memory consolidation and behavioral responses to the MWM.

of the hippocampal sub-regions. For example, as CA3 neurons form an attractor network, involved in generating very rapid representations of novel information (Kesner, 2007; Rolls, 2007), it is possible that the rapid increase in Egr-1 in CA3 neurons may play an important role in this process. The underlying mechanism behind such a rapid increase in Egr-1 protein is not known, however, a rapid increase in Egr-1 protein can be MAPK independent (Revest et al., 2005), and may represent a readily available pool of Egr-1 mRNA which can be rapidly translated in response to experience.

Although Arc mRNA increases were seen in the CA regions, Arc protein immuno-staining in the $\mathrm{CA}$ regions was indistinct and no visible change could be seen after MWM training. Arc mRNA in the CA regions is transported into the dendrites to be translated locally (Link et al., 1995; Steward et al., 1998; Steward and Worley, 2001), however, other studies have identified nuclear Arc protein staining in pyramidal neurons after exploration of a novel environment (Ramirez-Amaya et al., 2005; Vazdarjanova 
et al., 2006). The reason for this discrepancy is not known. In the DG, increases in numbers of Arc-positive neurons remained significantly higher than baseline even $8 \mathrm{~h}$ after MWM training. Such an extended Arc activation agrees with other studies which also found Arc in the DG to remain high $8 \mathrm{~h}$ after spatial exploration (Ramirez-Amaya et al., 2005; Vazdarjanova et al., 2006). Post $8 \mathrm{~h}$ time points would be necessary to ascertain just how long Arc remains elevated above baseline in DG neurons after MWM training. In addition to the role of Arc in cytoskeletal organization in the synapse, evidence is accumulating for a nuclear site of action of this IEG, namely that it may be involved in transcriptional regulation through interaction with the histone acetyl-transferase Tip60 (Wee et al., 2014).

The number of H3S10p- positive neurons in the DG $1 \mathrm{~h}$ after the start of training showed a significant positive correlation with the average latency to the platform during training. H3S10p is known to respond to psychological stressors including predator stress, novelty and forced swim stress, and not to physical stressors such as ether and cold exposure (Bilang-Bleuel et al., 2005; Chandramohan et al., 2007, 2008). It is therefore unlikely that the increased H3S10p in rats which took longer to find the platform is a result of the additional physical exertion. Previous observations have indicated that the magnitude of a DG $\mathrm{H} 3 \mathrm{~S} 10 \mathrm{p}$ response is dependent on the intensity of the stimulus (higher light intensity during novel environment exposure and lower water temperature during forced swimming leading to $\mathrm{H} 3 \mathrm{~S} 10 \mathrm{p}-\mathrm{K} 14 \mathrm{ac}$ formation in a larger proportion of neurons) (Bilang-Bleuel et al., 2005; Chandramohan et al., 2007, 2008). Furthermore, pre-treatment of rats with the anxiogenic drug FG7142 enhances the H3S10p-K14ac response to novelty in DG neurons (Papadopoulos et al., 2011). It is possible that a longer time in the maze, and therefore a more protracted exposure to an aversive condition (causing more stress, anxiety, and/or frustration), may prove to be a greater stimulus for neurons to undergo this specific histone modification. Whether this is the result of enhanced ERK MAPK signaling to the chromatin and/or increased glucocorticoid hormone secretion, or an as yet unknown mechanism would, however, need further investigation.

Unlike H3S10p, there was no correlation between performance in the maze and number of neurons expressing c-Fos, Egr-1, or Arc. This observation does not correspond with a previous study showing a significant negative correlation between latency to platform and Arc mRNA levels in the dorsal hippocampus (Guzowski et al., 2001). The studies are not entirely comparable, however, as RNA was measured in the dorsal hippocampus in the Guzowski et al. study, whereas we analyzed Arc protein expression specifically in DG neurons. Considering the significant correlation between H3S10p and the time spent in the maze, the lack of significant correlation between c-Fos and Egr-1 expression and behavioral performance was puzzling. It is particularly surprising given the high similarity in $\mathrm{H} 3 \mathrm{~S} 10 \mathrm{p}$, c-Fos, and Egr-1 responses in DG neurons after MWM (present study), FS and novelty stress (Chandramohan et al., 2007, 2008). Moreover, our ChIP experiments have shown the association of H3K9ac-S10p with the c-Fos and Egr-1 gene promoters. Thus, it seems that despite the similarity in response pattern, additional factors (e.g., protein stability, control of mRNA translation) are apparently playing an important role in shaping the IEG response in relation to behavioral performance.

There was remarkably little difference in IEG responses (either mRNA or protein) between MWM rats and SC rats, with the single exception of c-Fos, which was transiently higher in the SC group than the MWM group $1 \mathrm{~h}$ after the start of MWM training. Furthermore, there were no significant differences in the numbers of H3S10p positive neurons or in plasma corticosterone responses between the SC and MWM groups. Thus, phospho-acetylation of histone $\mathrm{H} 3$ and subsequent IEG activation is not selectively altered when a rat is learning the position of a target location within an environment. Instead, IEG expression was induced comparably in rats simply left to explore the environment, with no specific goal or task. This finding is in agreement with other studies which found no selective MWM changes in IEGs in the dorsal hippocampus compared with swim controls, procedural controls or visible platform controls (Guzowski et al., 2001; Shires and Aggleton, 2008). In contrast, Feldman et al. (2010) observed differential responses in IEG expression between MWM and swim controls, however, their swim controls swam only once which cannot be regarded as matched to the MWM condition (Feldman et al., 2010). In our study, the swim controls were exactly matched to the MWM animals in terms of both number and duration of swims.

Given the many studies that applied antisense oligodeoxynucleotide (ODN) technology and gene deletion models and found that IEGs play a critical role in spatial learning (Paylor et al., 1994; Guzowski et al., 2000; Jones et al., 2001; Guzowski, 2002; Plath et al., 2006; Czerniawski et al., 2011), it is surprising that MWM learning does not involve a greater induction of these genes in the hippocampus than the less complex swim control experience. Apparently, learning (e.g., the layout of the MWM room, the size and shape of the maze, the position of the cues) and the experience of stress is taking place in both groups, leading to associated IEG induction. Notably, learning can only be experimentally tested in the MWM groups but this doesn't exclude that the swim controls learn from their experience as well. In fact, swim control rats change their behavior across repeated trials in the maze (e.g., reduced speed and reduced thigmotaxis); this behavior implies reduced anxiety and indicates that they are learning from previous trials that escape around the walls of the maze is not possible (Carter et al., unpublished observation).

The dual histone mark $\mathrm{H} 3 \mathrm{~K} 9 \mathrm{ac}-\mathrm{S} 10 \mathrm{p}$ showed enrichment at the gene promoter regions of c-Fos and Egr-1, which significantly increased after SC or MWM exposure. This finding strongly indicates that this dual histone mark may be specifically involved in the induction of IEG transcription in response to introduction to the maze. Previously, we showed the association of the H3S10p mark with the c-Fos promoter in the forced swim model (Gutierrez-Mecinas et al., 2011). This association was specifically found in the hippocampus and not found in the neocortex, despite the fact that the neocortex also strongly expresses cFos after stress. Furthermore, although there was enrichment of $\mathrm{H} 3 \mathrm{~K} 9 \mathrm{ac}-\mathrm{S} 10 \mathrm{p}$ at the Arc gene promoter in all three experimental 
groups, there was no significant change after SC or MWM. This suggests that either phospho-acetylated histone $\mathrm{H} 3$ is not involved in the induction of this IEG or that the phosphoacetylated state at baseline is sufficient to allow gene induction if challenged.

Previously, we have postulated that whilst H3 phosphoacetylation allows the opening of the chromatin structure, binding of activated transcription factors like phosphorylated CREB to their recognition binding sites within the gene promoter is required for actual gene induction (Mifsud et al., 2011; Trollope et al., 2012). The H3K9ac-S10p ChIP results for cFos, Egr-1, and Arc imply that the role of H3K9ac-S10p in gene regulation may be highly gene specific. Further insight into differential association of $\mathrm{H} 3 \mathrm{~K} 9 \mathrm{ac}-\mathrm{S} 10 \mathrm{p}$ with genes associated with differential gene expression in the MWM model may be expected from ChIP combined with next-generation sequencing and RNA sequencing. From the present study we can conclude that, similar to the forced swim model, exploration of the MWM involves activation of the ERK MAPK pathway, formation of H3K9ac-S10p and induction of the IEGs c-Fos and Egr1 (Gutierrez-Mecinas et al., 2011; Reul, 2014; Reul et al., 2015).

To sum up, phosphorylation of S10 and acetylation of $\mathrm{K} 9$ and $\mathrm{K} 14$ in histone $\mathrm{H} 3$, and induction of the IEGs c-Fos, Egr-1, and Arc occurs in sparse DG granule in response to exploration of the maze, regardless of whether or not the rat is actively learning a platform location. The phospho-acetylation of histone $\mathrm{H} 3$ is attuned to the stimulus intensity (in this case the length of time

\section{References}

Adams, J. P., and Sweatt, J. D. (2002). Molecular psychology: roles for the ERK MAP kinase cascade in memory. Annu. Rev. Pharmacol. Toxicol. 42, 135-163. doi: 10.1146/annurev.pharmtox.42.082701.145401

Atkins, C. M., Selcher, J. C., Petraitis, J. J., Trzaskos, J. M., and Sweatt, J. D. (1998). The MAPK cascade is required for mammalian associative learning. Nat. Neurosci. 1, 602-609. doi: 10.1038/2836

Barratt, M. J., Hazzalin, C. A., Cano, E., and Mahadevan, L. C. (1994). Mitogen-stimulated phosphorylation of histone H3 is targeted to a small hyperacetylation-sensitive fraction. Proc. Natl. Acad. Sci. U.S.A. 91, 4781-4785. doi: $10.1073 /$ pnas.91.11.4781

Bilang-Bleuel, A., Ulbricht, S., Chandramohan, Y., De Carli, S., Droste, S. K., and Reul, J. M. H. M. (2005). Psychological stress increases histone H3 phosphorylation in adult dentate gyrus granule neurons: involvement in a glucocorticoid receptor-dependent behavioural response. Eur. J. Neurosci. 22, 1691-1700. doi: 10.1111/j.1460-9568.2005.04358.x

Blum, S., Moore, A. N., Adams, F., and Dash, P. K. (1999). A mitogen-activated protein kinase cascade in the CA1/CA2 subfield of the dorsal hippocampus is essential for long-term spatial memory. J. Neurosci. 19, 3535-3544.

Chandramohan, Y., Droste, S. K., Arthur, J. S. C., and Reul, J. M. H. M. (2008), The forced swimming-induced behavioural immobility response involves histone $\mathrm{H} 3$ phospho-acetylation and c-Fos induction in dentate gyrus granule neurons via activation of the N-methyl-D-aspartate/extracellular signalregulated kinase/mitogen- and stress-activated kinase signalling pathway. Eur. J. Neurosci. 27, 2701-2713. doi: 10.1111/j.1460-9568.2008.06230.x

Chandramohan, Y., Droste, S. K., and Reul, J. M. H. M. (2007). Novelty stress induces phospho-acetylation of histone $\mathrm{H} 3$ in rat dentate gyrus granule neurons through coincident signalling via the $\mathrm{N}$-methyl-D-aspartate receptor and the glucocorticoid receptor: relevance for c-fos induction. J. Neurochem. 101, 815-828. doi: 10.1111/j.1471-4159.2006.04396.x spent in the maze) and is directly associated with the c-Fos and Egr-1 promoters after exploration in the maze. There was very little difference either in IEG expression or in the extent of association of $\mathrm{H} 3 \mathrm{~K} 9 \mathrm{ac}-\mathrm{S} 10 \mathrm{p}$ with the IEG promoters between the MWM trained and swim control groups. This remains a conundrum in the face of the well-known critical dependence of behavioral performance in the MWM model on these IEGs from ODN and gene deletion studies. Therefore, we postulate that distinct AP1- and Egr-1-induced (second wave) genes may shape specific spatial learning-associated molecular processes in hippocampal neurons.

\section{Acknowledgments}

This study was supported by grants from the Biotechnology and Biological Sciences Research Council (BBSRC; Grant no. BB/K007408/1) and the British Pharmacological Society's Integrative Pharmacology Fund (IPF), and a Medical Research Council (MRC)-funded PhD studentship to SC. The authors wish to thank the contributions of Drs Emily Saunderson, Maria Gutierrez-Mecinas, Alexandra Trollope and Jason Pont. The authors have no potential conflicts of interest to declare.

\section{Supplementary Material}

The Supplementary Material for this article can be found online at: http://journal.frontiersin.org/article/10.3389/fnbeh. 2015.00156/abstract

Cheung, P., Allis, C. D., and Sassone-Corsi, P. (2000a). Signaling to chromatin through histone modifications. Cell 103, 263-271. doi: 10.1016/S00928674(00)00118-5

Cheung, P., Tanner, K. G., Cheung, W. L., Sassone-Corsi, P., Denu, J. M., and Allis, C. D. (2000b). Synergistic coupling of histone H3 phosphorylation and acetylation in response to epidermal growth factor stimulation. Mol. Cell 5, 905-915. doi: 10.1016/S1097-2765(00)80256-7

Chwang, W. B., Arthur, J. S., Schumacher, A., and Sweatt, J. D. (2007). The nuclear kinase mitogen- and stress-activated protein kinase 1 regulates hippocampal chromatin remodeling in memory formation. J. Neurosci. 27, 12732-12742. doi: 10.1523/JNEUROSCI.2522-07.2007

Chwang, W. B., O'Riordan, K. J., Levenson, J. M., and Sweatt, J. D. (2006). ERK/MAPK regulates hippocampal histone phosphorylation following contextual fear conditioning. Learn. Mem. 13, 322-328. doi: 10.1101/lm. 152906

Crosio, C., Heitz, E., Allis, C. D., Borrelli, E., and Sassone-Corsi, P. (2003). Chromatin remodeling and neuronal response: multiple signaling pathways induce specific histone $\mathrm{H} 3$ modifications and early gene expression in hippocampal neurons. J. Cell Sci. 116, 4905-4914. doi: 10.1242/jcs. 00804

Czerniawski, J., Ree, F., Chia, C., Ramamoorthi, K., Kumata, Y., and Otto, T. A. (2011). The importance of having arc: expression of the immediateearly gene arc is required for hippocampus-dependent fear conditioning and blocked by NMDA receptor antagonism. J. Neurosci. 31, 11200-11207. doi: 10.1523/JNEUROSCI.2211-11.2011

Davis, S., Vanhoutte, P., Pages, C., Caboche, J., and Laroche, S. (2000). The MAPK/ERK cascade targets both Elk-1 and cAMP response element-binding protein to control long-term potentiation-dependent gene expression in the dentate gyrus in vivo. J. Neurosci. 20, 4563-4572.

Deak, M., Clifton, A. D., Lucocq, J. M., and Alessi, D. R. (1998). Mitogen- and stress-activated protein kinase-1 (MSK1) is directly activated by MAPK and 
SAPK2/p38, and may mediate activation of CREB. EMBO J. 17, 4426-4441. doi: 10.1093/emboj/17.15.4426

De Kloet, E. R., Dekock, S., Schild, V., and Veldhuis, H. D. (1988). Antiglucocorticoid RU-38486 attenuates retention of a behavior and disinhibits the hypothalamic-pituitary adrenal axis at different brain sites. Neuroendocrinology 47, 109-115. doi: 10.1159/000124900

Feldman, L. A., Shapiro, M. L., and Nalbantoglu, J. (2010). A novel, rapidly acquired and persistent spatial memory task that induces immediate early gene expression. Behav. Brain Funct. 6, 11. doi: 10.1186/1744-90 81-6-35

Gutierrez-Mecinas, M., Trollope, A. F., Collins, A., Morfett, H., Hesketh, S. A., Kersante, F., et al. (2011). Long-lasting behavioral responses to stress involve a direct interaction of glucocorticoid receptors with ERK1/2MSK1-Elk-1 signaling. Proc. Natl. Acad. Sci. U.S.A. 108, 13806-13811. doi: 10.1073/pnas.1104383108

Guzowski, J. F. (2002). Insights into immediate-early gene function in hippocampal memory consolidation using antisense oligonucleotide and fluorescent imaging approaches. Hippocampus 12, 86-104. doi: 10.1002/hipo.10010

Guzowski, J. F., Lyford, G. L., Stevenson, G. D., Houston, F. P., McGaugh, J. L., Worley, P. F., et al. (2000). Inhibition of activity-dependent arc protein expression in the rat hippocampus impairs the maintenance of long-term potentiation and the consolidation of long-term memory. J. Neurosci. 20, 3993-4001.

Guzowski, J. F., Setlow, B., Wagner, E. K., and McGaugh, J. L. (2001). Experiencedependent gene expression in the rat hippocampus after spatial learning: a comparison of the immediate-early genes Arc, c-fos, and zif268. J. Neurosci. 21, 5089-5098.

Jones, M. W., Errington, M. L., French, P. J., Fine, A., Bliss, T. V. P., Garel, S., et al. (2001). A requirement for the immediate early gene Zif268 in the expression of late LTP and long-term memories. Nat. Neurosci. 4, 289-296. doi: $10.1038 / 85138$

Kersante, F., Rowley, S. C. S., Pavlov, I., Gutierrez-Mecinas, M., Semyanov, A., Reul, J. M. H. M., et al. (2013). A functional role for both gammaaminobutyric acid (GABA) transporter-1 and GABA transporter-3 in the modulation of extracellular GABA and GABAergic tonic conductances in the rat hippocampus. J. Physiol. Lond. 591, 2429-2441. doi: 10.1113/jphysiol.2012.246298

Kesner, R. P. (2007). Behavioral functions of the CA3 subregion of the hippocampus. Learn. Mem. 14, 771-781. doi: 10.1101/lm.688207

Link, W., Konietzko, U., Kauselmann, G., Krug, M., Schwanke, B., Frey, U., et al. (1995). Somatodendritic expression of an immediate-early gene is regulated by synaptic activity. Proc. Natl. Acad. Sci. U.S.A. 92, 5734-5738. doi: 10.1073/pnas.92.12.5734

Mifsud, K. R., Gutierrez-Mecinas, M., Trollope, A. F., Collins, A., Saunderson, E. A., and Reul, J. M. H. M. (2011). Epigenetic mechanisms in stress and adaptation. Brain Behav. Immun. 25, 1305-1315. doi: 10.1016/j.bbi.2011.06.005

Nowak, S. J., and Corces, V. G. (2000). Phosphorylation of histone H3 correlates with transcriptionally active loci. Genes Dev. 14, 3003-3013. doi: $10.1101 /$ gad. 848800

Oitzl, M. S., and De Kloet, E. R. (1992). Selective corticosteroid antagonists modulate specific aspects of spatial orientation learning. Behav. Neurosci. 106, 62-71. doi: 10.1037/0735-7044.106.1.62

Oitzl, M. S., Reichardt, H. M., Joels, M., and De Kloet, E. R. (2001). Point mutation in the mouse glucocorticoid receptor preventing DNA binding impairs spatial memory. Proc. Natl. Acad. Sci. U.S.A. 98, 12790-12795. doi: 10.1073/pnas.231313998

Papadopoulos, A., Chandramohan, Y., Collins, A., Droste, S. K., Nutt, D. J., and Reul, J. M. (2011). GABAergic control of novelty stress-responsive epigenetic and gene expression mechanisms in the rat dentate gyrus. Eur. Neuropsychopharmacol. 21, 316-324. doi: 10.1016/j.euroneuro.2010.05.005

Paxinos, G., and Watson, C. (2007). The Rat Brain in Stereotaxic Coordinates, 6th Edn. London: Academic Press.

Paylor, R., Johnson, R. S., Papaioannou, V., Spiegelman, B. M., and Wehner, J. M. (1994). Behavioral-assessment of c-Fos mutant mice. Brain Res. 651, 275-282. doi: 10.1016/0006-8993(94)90707-2

Pfaffl, M. W. (2001). A new mathematical model for relative quantification in real-time RT-PCR. Nucleic Acids Res. 29, 6. doi: 10.1093/nar/29.9.e45
Plath, N., Ohana, O., Dammermann, B., Errington, M. L., Schmitz, D., Gross, C., et al. (2006). Arc/Arg3.1 is essential for the consolidation of synaptic plasticity and memories. Neuron 52, 437-444. doi: 10.1016/j.neuron.2006.08.024

Ramirez-Amaya, V., Vazdarjanova, A., Mikhael, D., Rosi, S., Worley, P. F., and Barnes, C. A. (2005). Spatial exploration-induced Arc mRNA and protein expression: evidence for selective, network-specific reactivation. J. Neurosci. 25, 1761-1768. doi: 10.1523/JNEUROSCI.4342-04.2005

Reul, J. M. H. M. (2014). Making memories of stressful events: a journey along epigenetic, gene transcription, and signaling pathways. Front. Psychiatry 5:5. doi: $10.3389 /$ fpsyt.2014.00005

Reul, J. M. H. M., Collins, A., Saliba, R. S., Mifsud, K. R., Carter, S. D., GutierrezMecinas, M., et al. (2015). Glucocorticoids, epigenetic control and stress resilience. Neurobiol. Stress 1, 44-59. doi: 10.1016/j.ynstr.2014.10.001

Reul, J. M. H. M., Hesketh, S. A., Collins, A., and Mecinas, M. G. (2009). Epigenetic mechanisms in the dentate gyrus act as a molecular switch in hippocampusassociated memory formation. Epigenetics 4, 434-439. doi: 10.4161/epi.4. 7.9806

Revest, J. M., Di Blasi, F., Kitchener, P., Rouge-Pont, F., Desmedt, A., Turiault, M., et al. (2005). The MAPK pathway and Egr-1 mediate stress-related behavioral effects of glucocorticoids. Nat. Neurosci. 8, 664-672. doi: 10.1038/nn1441

Rolls, E. T. (2007). An attractor network in the hippocampus: theory and neurophysiology. Learn. Mem. 14, 714-731. doi: 10.1101/lm.631207

Sandi, C., Loscertales, M., and Guaza, C. (1997). Experience-dependent facilitating effect of corticosterone on spatial memory formation in the water maze. Eur. J. Neurosci. 9, 637-642. doi: 10.1111/j.1460-9568.1997.tb01412.x

Schneider, C. A., Rasband, W. S., and Eliceiri, K. W. (2012). NIH image to imageJ: 25 years of image analysis. Nat. Methods 9, 671-675. doi: 10.1038/nmeth.2089

Shires, K. L., and Aggleton, J. P. (2008). Mapping immediate-early gene activity in the rat after place learning in a water-maze: the importance of matched control conditions. Eur. J. Neurosci. 28, 982-996. doi: 10.1111/j.14609568.2008.06402.x

Shors, T. J. (2001). Acute stress rapidly and persistently enhances memory formation in the male rat. Neurobiol. Learn. Mem. 75, 10-29. doi: 10.1006/nlme.1999.3956

Steward, O., Wallace, C. S., Lyford, G. L., and Worley, P. F. (1998). Synaptic activation causes the mRNA for the IEG Arc to localise selectively near activated postsynaptic sites on dendrites. Neuron 21, 741-751. doi: 10.1016/S08966273(00)80591-7

Steward, O., and Worley, P. F. (2001). Selective targeting of newly synthesized Arc mRNA to active synapses requires NMDA receptor activation. Neuron 30, 227-240. doi: 10.1016/S0896-6273(01)00275-6

Trollope, A. F., Gutierrez-Mecinas, M., Mifsud, K. R., Collins, A., Saunderson, E. A., and Reul, J. M. H. M. (2012). Stress, epigenetic control of gene expression and memory formation. Exp. Neurol. 233, 3-11. doi: 10.1016/j.expneurol.2011.03.022

Vazdarjanova, A., Ramirez-Amaya, V., Insel, N., Plummer, T. K., Rosi, S., Chowdhury, S., et al. (2006). Spatial exploration induces ARC, a plasticityrelated immediate-early gene, only in calcium/calmodulin-dependent protein kinase II-positive principal excitatory and inhibitory neurons of the rat forebrain. J. Comp. Neurol. 498, 317-329. doi: 10.1002/cne.21003

Wee, C. L., Teo, S., Oey, N. E., Wright, G. D., Vandongen, H. M. A., and Vandongen, A. M. J. (2014). Nuclear arc interacts with the histone acetyltransferase tip60 to modify $\mathrm{H} 4 \mathrm{~K} 12$ acetylation. eNeuro 1. doi: 10.1523/ENEURO.0019-14.2014

Xia, Z. G., Dudek, H., Miranti, C. K., and Greenberg, M. E. (1996). Calcium influx via the NMDA receptor induces immediate early gene transcription by a MAP kinase/ERK-dependent mechanism. J. Neurosci. 16, 5425-5436.

Conflict of Interest Statement: The authors declare that the research was conducted in the absence of any commercial or financial relationships that could be construed as a potential conflict of interest.

Copyright $\odot 2015$ Carter, Mifsud and Reul. This is an open-access article distributed under the terms of the Creative Commons Attribution License (CC BY). The use, distribution or reproduction in other forums is permitted, provided the original author(s) or licensor are credited and that the original publication in this journal is cited, in accordance with accepted academic practice. No use, distribution or reproduction is permitted which does not comply with these terms. 